\title{
World Health Organization grading classification for pancreatic neuroendocrine neoplasms: a comprehensive analysis from a large Chinese institution
}

Min Yang ${ }^{1}$, Lin Zeng ${ }^{2}$, Neng-wen Ke ${ }^{3}$, Chun-lu Tan ${ }^{3}$, Bo-le Tian ${ }^{3}$, Xu-bao Liu ${ }^{3}$, Bo Xiang ${ }^{1+}$ and Yi Zhang ${ }^{3^{*+}}$ (D)

\begin{abstract}
Background: Pancreatic neuroendocrine neoplasms (p-NENs) are a group of highly heterogeneous tumors with distinct clinicopathological features and long-term prognosis. In 2017, in order to better stratify patients into prognostic groups and predicting their outcomes, World Health Organization (WHO) officially updated its grading system for p-NENs which distinguished these neoplasms among Grading 1 (G1) pancreatic neuroendocrine tumors (p-NETs), G2 p-NETs, G3 p-NETs and G3 pancreatic neuroendocrine carcinomas (p-NECs). However, this new grading classification for p-NENs has not yet been rigorously validated.
\end{abstract}

Methods: Data of patients who were surgically treated and histopathologically diagnosed as p-NENs at West China Hospital of Sichuan University from January 2002 to December 2018 were retrospectively collected and analyzed according the novel WHO 2017 grading classification.

Results: We eventually enrolled 480 eligible patients with p-NENs in our present study, in which 150 patients with WHO 2017 G1 p-NETs, 158 with G2 p-NETs, 64 with G3 p-NETs and 108 with G3 p-NECs were identified. The estimated 5-year overall survival for patients with G1 p-NETs, G2 p-NETs, G3 p-NETs and G3 p-NECs was 75.8, 58.4, 35.1 and 11.1\%, with a median survival time of $85.3 \mathrm{mons}, 67.4 \mathrm{mons}, 51.3 \mathrm{mons}$ and $26.8 \mathrm{mons}$, respectively. Patients with G2 p-NETs present notably worse survival than those with $G 1$ p-NETs $(P=0.03)$. Survival of $G 3$ p-NETs were significantly worse than that of $G 1 p$-NETs or G2 p-NETs $(P<0.001, P=0.023$, respectively), as well as that when comparing G3 p-NECs with G1 p-NETs or G2 p-NETs $(P<$ $0.001, P<0.001$, respectively). Patients with G3 p-NECs showed statistically shorter survival than those with G3 p-NETs $(P<$ 0.001). Both WHO 2017 and 2010 grading criteria could be independent predictor for the OS of p-NENs $(P=0.016, P=0.022$; respectively). The 95\% confidence intervals of WHO 2017 grading classification (0.983-9.454) was slightly smaller than that of WHO 2010 criteria (0.201-13.374), indicating a relatively more accurate predicting ability for the prognosis of p-NENs.

(Continued on next page)

\footnotetext{
*Correspondence: zhangyide520@163.com

${ }^{\dagger}$ Bo Xiang and Yi Zhang contributed equally to this work.

${ }^{3}$ Department of Pancreatic Surgery, West China Hospital of Sichuan

University, Chengdu, Sichuan Province, the People's Republic of China, No.37,

Guoxue Road, Wuhou District, Chengdu, Sichuan Province, the People's

Republic of China

Full list of author information is available at the end of the article
}

(c) The Author(s). 2020 Open Access This article is licensed under a Creative Commons Attribution 4.0 International License, which permits use, sharing, adaptation, distribution and reproduction in any medium or format, as long as you give appropriate credit to the original author(s) and the source, provide a link to the Creative Commons licence, and indicate if changes were made. The images or other third party material in this article are included in the article's Creative Commons licence, unless indicated otherwise in a credit line to the material. If material is not included in the article's Creative Commons licence and your intended use is not permitted by statutory regulation or exceeds the permitted use, you will need to obtain permission directly from the copyright holder. To view a copy of this licence, visit http://creativecommons.org/licenses/by/4.0/ The Creative Commons Public Domain Dedication waiver (http://creativecommons.org/publicdomain/zero/1.0/) applies to the data made available in this article, unless otherwise stated in a credit line to the data. 
(Continued from previous page)

Conclusion: The WHO 2017 grading classification for p-NENs could successfully allocate patients into four groups with distinct clinical features and significant survival differences, which might be superior to the WHO 2010 criteria for its better prognostic stratification and more accurate predicting ability.

Keywords: PANCREATIC neuroendocrine neoplasms, WHO, Grading, AJCC, Staging, Prognosis

\section{Background}

Pancreatic neuroendocrine neoplasms ( $\mathrm{p}-\mathrm{NENs}$ ), namely islet cell tumors, are a group of highly heterogeneous tumors with different clinical manifestations, pathological features and long-term prognosis $[1,2]$. Although p-NENs are uncommon in reported literature, data from the United States indicated that the incidence of p-NENs has increased obviously from $1.09 / 100,000$ to $6.98 / 100,000$ in recent decades, probably due to the development of endoscopic and radiological screening as well as the improvement of clinical awareness and diagnostic techniques for p-NENs, which has resulted in more and more attention being paid to these diseases [2-4].

Due to their pathologic heterogeneity and a spectrum of clinical behaviors of $\mathrm{p}-\mathrm{NENs}$, the criteria for predicting prognosis within uniformly classified tumors have been unsatisfactory [5]. In 2006, the European Neuroendocrine Tumor Society (ENETS) firstly proposed a separate grading system based on the cut-off point of mitotic rate per 10 high power fields (HPFs) and Ki-67 proliferative index, which defined p-NENs as Grading 1 (G1) pancreatic neuroendocrine tumors (p-NETs), G2 pNETs and G3 pancreatic neuroendocrine carcinomas ("G3 p-NECs") [6]. The ENETS grading scheme was later adopted in the World Health Organization (WHO) 2010 classification of neuroendocrine neoplasms because of increasing supportive evidence of its predictive power for the survival of p-NENs (Table 1) [8]. The G1/G2 pNETs were regarded as well-differentiated in the designated ENETS/WHO grading system, while the "G3 pNECs" were poorly-differentiated, which could present significantly different genetic, biological, treatment and survival features [9-13].

In 2017, relying mainly on some established histopathologic criteria to better predict the tumor's grade and biological behaviors, WHO officially classified p-NENs into 2 broad categories in its newly-updated grading classification (Table 1): well-differentiated p-NETs which consist of G1 p-NETs $(<2$ mitoses per $10 \mathrm{HPFs}$ and a Ki-67 proliferation index $<3 \%$ ), G2 p-NETs (between 2

Table 1 Definitions of the WHO 2017 and 2010 grading classification for p-NENs and distributions of patients in the present study according to these two criteria

\begin{tabular}{|c|c|c|c|}
\hline \multicolumn{3}{|l|}{ Definitions } & \multirow{2}{*}{$\begin{array}{l}\text { Distributions } \\
\text { Cases(\%) }\end{array}$} \\
\hline Classification & $\begin{array}{l}\text { Mitotic } \\
\text { rate }^{\mathbf{A}}\end{array}$ & $\begin{array}{l}\text { Ki-67 proliferation index } \\
(\%)^{\mathbf{B}}\end{array}$ & \\
\hline \multicolumn{4}{|l|}{ WHO 2017 grading criteria [7] } \\
\hline \multicolumn{4}{|l|}{ Well-differentiated p-NENs: } \\
\hline NET G1 & $<2$ & $<3$ & $150(31.3 \%)$ \\
\hline NET G2 & $2-20$ & $3-20$ & $158(32.9 \%)$ \\
\hline NET G3 & $>20$ & $>20$ & $64(13.3 \%)$ \\
\hline \multicolumn{4}{|l|}{ Poorly-differentiated p-NENs: } \\
\hline NEC G3 (small cell and large cell subtypes) & $>20$ & $>20$ & $108(22.5 \%)$ \\
\hline \multicolumn{4}{|l|}{ WHO 2010 grading criteria [8] } \\
\hline \multicolumn{4}{|l|}{ Well-differentiated endocrine tumor, G1: } \\
\hline NET G1 & $<2$ & $<3$ & $150(31.3 \%)$ \\
\hline \multicolumn{4}{|l|}{ Well-differentiated endocrine tumor, G2: } \\
\hline NET G2 & $2-20$ & $3-20$ & $158(32.9 \%)$ \\
\hline \multicolumn{4}{|c|}{$\begin{array}{l}\text { Poorly-differentiated neoplasm: neuroendocrine carcinoma, G3 (small cell and large cell } \\
\text { type): }\end{array}$} \\
\hline “NEC G3” & $>20$ & $>20$ & $172(35.8 \%)$ \\
\hline
\end{tabular}

A: The mitotic rate is based on the evaluation of mitoses in 50 high power fields in areas of higher density, and is expressed as mitoses per 10 high power fields B: The Ki-67 proliferation index is based on the evaluation of $\geq 500$ cell in areas of higher nuclear labeling (hot spot)

Abbreviation: WHO World Health Organization; $p$-NENs Pancreatic neuroendocrine neoplasms; NET Neuroendocrine tumors; NEC Neuroendocrine carcinoma; G Grading 
and 20 mitoses per $10 \mathrm{HPFs}$ or a Ki-67 proliferation index ranging between 3 and 20\%) and G3 p-NETs (> 20 mitoses per $10 \mathrm{HPFs}$ or a Ki-67 proliferation index > $20 \%$ without poorly-differentiated pathological features), and poorly-differentiated p-NECs which referred to G3 p-NECs having $>20$ mitoses per $10 \mathrm{HPFs}$ or a Ki-67 proliferation index $>20 \%$ with poorly-differentiated small cell or large cell features [14].

The purpose of WHO 2017 grading classification for p-NENs was to improve the prediction of clinical outcomes and to determine better therapeutic strategies and patient care, which has not yet been assessed thoroughly. Whether it could better stratify p-NENs into prognostic groups and predicting their outcome has still been uncertain. In the present study, based on the relevant data from a large Chinese institution, we aimed to validate the clinical value of the WHO 2017 grading classification for p-NENs. To accomplish this, we analyzed the distribution characteristics and survival differences between each new WHO grading group. Then, we made comparisons between the WHO 2017 grading system and WHO 2010 criteria on stratifying and predicting significance for the outcome of p-NENs.

\section{Methods}

\section{Patients enrollment}

In the present study, we retrospectively reviewed the electronic or paper-based medical records of patients who were surgically treated and histopathologically diagnosed as p-NENs from January 2002 to December 2018 at West China Hospital of Sichuan University. We excluded patients who were only clinically suspected with related symptoms or signs but no postoperative pathological confirmation of p-NENs, as well as some patients with hereditary syndromes which were extremely rare. For included cases, we prospectively collected the relevant data such as demographic baseline, clinical presentation, imaging information, surgical procedure, perioperative outcome, etc. Our research was approved by the institutional review board of West China Hospital of Sichuan University and written informed consent was acquired on admission from all patients for their information to be used for studying purpose, which was in accordance with the general principles of the Helsinki Declaration [15].

\section{Tumor features}

According to some recognized criteria $[8,16,17]$, morphologically well-differentiated p-NENs were marked by typical neuroendocrine architectural tissues with organoid features and tumor cells with low nucleocytoplasmic ratio, abundant eosinophilic or amphophilic cytoplasm, and ovoid nuclei with salt and pepper chromatin containing well-defined nucleoli, while morphologically poorly- differentiated p-NENs were featured on nodular or solid architecture lack of organoid traits, usually with high nucleocytoplasm ratio and multifocal or extensive tumor necrosis, including small cell and large cell subtypes. For enrolled patients in the present study, all surgical specimens from tumor tissues were re-stained with hematoxylin-eosin and immunohistochemical methods, which were microscopically reviewed again by experienced pathologists in our institution. Their histopathologic analyzing results, such as morphological feature, differentiated degree, mitotic count, Ki-67 positive proliferation index, etc. were systematically documented in the prepared tabulations. After that, all p-NENs were defined into four groups of NET G1, NET G2, NET G3 and NEC G3 based on both morphological and immunohistochemical features according to their definition by WHO 2017 grading classification [14]. In terms of the tumor-node-metastasis (TNM) classification, the 8th edition of American Joint Committee on Cancer (AJCC) staging manual for p-NENs was applied respectively to different grading groups of $\mathrm{p}$ NENs by combining the reports from both preoperative imaging findings, intraoperative surgical data and postoperative pathological results (in this new manual, one system was specifically proposed for G1/G2/ p-NETs, the other for "G3 p-NECs") [18].

\section{Follow-up procedure}

Follow-up was mainly conducted by telephone, e-mail, mail, or outpatient clinic review between July and December of 2019, leading to a median follow-up time of 40.8mon (Ranging 11.5-190.4mons). The primary outcome was overall survival (OS), which was calculated either as the time in months between the date of surgery and the date of death or last follow-up, and presented as either median survival time (MST) or estimated 5-year OS with a hazard ratio (HR) and 95\% confidence intervals (CIs). Patients who were lost to follow-up were excluded in the final survival analysis models.

\section{Statistical analysis}

Quantitative variables were reported as mean with standard deviation (SD) or median and compared using the Student's t or the analysis of variance test. Categorical variables were presented as numbers with their frequencies as proportions (\%) and compared using the Chi-square test or Fisher's exact test. OS estimates and curves of relevant factors were generated and plotted using the Kaplan-Meier (K-M) method and compared using the log-rank test. Univariate and multivariate analysis were designed using Cox Regression proportional hazards model to validate the predicting value of the WHO 2017 grading classification for the OS of p-NENs. Difference with a two-sided $P$ value less than 0.05 was considered statistically significant. All statistical analyses 
were carried out using IBM SPSS 25.0 statistical software.

\section{Results}

In our present study, 150, 158, 64 and 108 patients were respectively classified into the G1/G2/G3 p-NETs and G3 p-NECs group, while 172 patients were defined as WHO 2010 "NEC G3". The baseline demographics and tumor characteristics of p-NENs distributed by WHO 2017 and 2010 grading classification were revealed in Table 2. Comparisons of patient age $(50 \mathrm{yrs}$. vs. $57 \mathrm{yrs.}$, respectively, $P=0,034)$ and tumor diameter $(3.5 \mathrm{~cm}$ vs. $5.6 \mathrm{~cm}$, respectively, $P=0.027$ ) between $\mathrm{G} 1 / \mathrm{G} 2 / \mathrm{G} 3 \mathrm{p}$ NETs (i.e. well-differentiated p-NENs; $N=372$ ) and G3 p-NECs (i.e. poorly-differentiated p-NENs; $N=108$ ) were notably significant, while those of patient gender, functional status, incidental diagnosis, diagnosis period, tumor location, surgical margin and postoperative medical therapy present no statistical differences $(P>0.05)$. Compared with G1/G2/G3 p-NETs, G3 p-NECs exhibit more vascular infiltration $(32.4 \%$ vs. $17.2 \%$, respectively, $P=0.035)$, lymph involvement ( $46.3 \%$ vs. $29.3 \%$, respectively, $P=0.019)$ and distant metastasis $(29.6 \%$ vs. $16.7 \%$, respectively, $P=0.041$ ).

When the follow-up ended, there were 120 patients with G1 p-NETs, 120 with G2 p-NETs, 55 with G3 pNETs and 85 with G3 p-NECs in touch, in which 44, 48, 28 and 56 patients respectively died due to the progression of p-NENs (Table 2). The 5-year OS for patients with G1/G2/G3 p-NETs and G3 p-NECs was 75.8, 58.4, 35.1 and $11.1 \%$, respectively, with a MST of 85.3 mons (95\% CIs: 72.2-98.4), 67.4mons (95\% CIs: 58.7-76.1), 51.3mons (95\% CIs: $46.3-56.3$ ) and 26.8 mons (95\% CIs: 22.8-30.8), while that for patients with WHO 2010 "G3 p-NECs" was $21.2 \%$, with a MST of 34.5 mon (95\% CIs: 28.9-40.1). Patients with G1 p-NETs by WHO 2017 or 2010 criteria present notably better survival than those with G2 p-NETs $(P=0.03$, Fig. $1 ; P=0.03$, Fig. 2 ; respectively). Survival of the WHO 2017 G3 p-NETs were significantly worse than that of G1 p-NETs $(P<0.001)$ or G2 p-NETs $(P=0.023$; Fig. 1$)$, as well as that when comparing G3 p-NECs with G1 p-NETs $(P<0.001)$ or G2 p-NETs $(P<0.001$; Fig. 1$)$, while patients with G3 pNECs also showed statistically shorter survival than those with G3 p-NETs $(P<0.001$; Fig. 1$)$. Patients with WHO 2010 "G3 p-NECs" present worse survival than those with G1 p-NETs $(P<0.001)$ or G2 p-NETs $(P<$ 0.001; Fig. 2) as well.

The diverse clinicopathological features of each new grading group of p-NENs has led to significant different distributions of tumor stage (Table 2). For G1/G2/G3 pNETs, by applying one AJCC 2017 TNM staging system which was originally proposed for G1/G2 p-NETs, there were respectively 116, 108, 86 and 62 patients defined in
Stage I, Stage II, Stage III and Stage IV. The estimated 5 -year OS of patients in each new stage was 89.2, 70.5, 51.2 and $18.9 \%$, respectively, with a MST of 89.7 mons (95\% CIs: 76.1-103.3), not reached, 61.2mons (95\% CIs: 52.5-69.9) and 35.5mons (95\% CIs: 19.8-51.5). Patients in Stage I or Stage II both showed notably longer survivals than those in Stage III $(P<0.001, P<0.001$; respectively) or Stage IV $(P=0.001, P<0.001$; respectively; Fig. 3). Moreover, there were also significant survival differences when comparing Stage I with Stage II $(P=$ $0.037)$ or Stage III with Stage IV $(P=0.001$, Fig. 3). For G3 p-NECs, by using the other new AJCC staging system which was primarily suggested for "G3 p-NECs", 18, 30, 28 and 32patients were respectively distributed from Stage I to Stage IV. The calculated 3-year OS for patients in each new stage was 80.8, 33.2, 7.1\% and NA, respectively, with a MST of 55.4 mons (95\% CIs: $22.3-$ 88.5), 30.6mons (95\% CIs: 28.6-32.6), 25.6mons (95\% CIs: $23.3-27.9)$ and 14.3 mons (95\% CIs: $12.2-16.4)$. Patients in Stage I or Stage II present statistically better survivals than those in Stage III $(P<0.001, P<0.001$; respectively) or Stage IV ( $P=0.023, P<0.001$; respectively; Fig. 4). Meanwhile, survival differences when comparing Stage I with Stage II $(P=0.014)$ or Stage III with Stage IV $(P<0.001$; Fig. 4$)$ were also significant.

Using Cox Regression proportional hazards models, we performed univariate and multivariate analysis to evaluate the predicting value of certain factors with the OS of $\mathrm{p}$ NENs (Table 3). According to our demonstrations, patient gender and age, tumor location and incidental diagnosis weren't statistically significant in univariate analysis $(P>$ 0.05 ), while functional status, tumor diameter and postoperative medical therapy were not significant in multivariate analysis $(\mathrm{P}>0.05)$. Radical resection, vascular infiltration, lymph involvement, distant metastasis and grading by WHO 2017 and 2010 criteria were statistically significant in both univariate $(P<0.05)$ and multivariate analysis $(P<0.05)$. Our analysis revealed that both WHO 2017 and 2010 grading criteria could be independent predictor for the OS of p-NENs $(P=0.016, P=0.022$; respectively). The 95\% CIs of WHO 2010 grading classification (0.201-13.374) was slightly larger than that of WHO 2017 criteria (0.983-9.454), indicating a relatively inaccurate predicting ability.

\section{Discussion}

A uniform classification for p-NENs has been lacking to stratify p-NENs into prognostic groups, although several varying systems have been devised, analyzed, and compared for p-NENs $[20,21]$. In 2010, the WHO grading system distinguished G1 p-NETs from G2 p-NETs and "G3 p-NECs" based on mitotic rate and Ki-67 proliferative index $[6,8]$, which has been proven to be prognostic for the OS of p-NENs [9-13]. Although the WHO 2010 
Table 2 Clinical features of p-NENs in the present study according to the WHO 2017 and 2010 grading classification

\begin{tabular}{|c|c|c|c|c|c|c|c|c|}
\hline \multirow[t]{2}{*}{ Factor } & \multicolumn{2}{|c|}{$\begin{array}{l}\text { WHO 2017/2010 } \\
\text { criteriaA }^{\text {A }}\end{array}$} & \multicolumn{3}{|c|}{ WHO 2017 criteria $^{A}$} & \multirow{2}{*}{$\begin{array}{l}\text { WHO } 2010 \\
\text { criteriaA }^{\mathbf{A}} \\
\text { "NEC G3" } \\
(\boldsymbol{N}=172) \\
\end{array}$} & \multirow{2}{*}{\multicolumn{2}{|c|}{$\begin{array}{l}\text { All } \\
(\boldsymbol{N}=480)\end{array}$}} \\
\hline & $\begin{array}{l}\text { NET G1 } \\
(\boldsymbol{N}=150)\end{array}$ & $\begin{array}{l}\text { NET G2 } \\
(\boldsymbol{N}=158)\end{array}$ & $\begin{array}{l}\text { NET G3 } \\
(\boldsymbol{N}=64)\end{array}$ & & $\begin{array}{l}\text { NEC G3 } \\
(\boldsymbol{N}=108)\end{array}$ & & & \\
\hline \multicolumn{9}{|l|}{ Gender } \\
\hline Female & $\begin{array}{l}88 \\
(58.7 \%)\end{array}$ & 97 (61.4\%) & $38(59.4 \%)$ & & $62(57.5 \%)$ & $100(58.1 \%)$ & $285(59.4 \%)$ & \\
\hline \multicolumn{9}{|l|}{ Age, yrs. } \\
\hline Mean \pm SD & $45.7 \pm 15$ & $49.1 \pm 8.5$ & $50.2 \pm 7.8$ & & $54.1 \pm 9.2$ & $52.7 \pm 10$ & $49.5 \pm 8.6$ & \\
\hline Median & 2 & 48 & 52 & & 57 & 253 & 50 & \\
\hline Range & $457-68$ & $12-82$ & $7-71$ & & $14-80$ & $7-80$ & $7-82$ & \\
\hline Tumor size, cm. & $2.9 \pm 2.1$ & $5.5 \pm 2.8$ & $5.6 \pm 3.5$ & & $5.9 \pm 4.1$ & $5.1 \pm 3.9$ & $5.6 \pm 4.8$ & \\
\hline Mean \pm SD & 2.0 & 4.0 & 4.5 & & 5.6 & 5.1 & 4.0 & \\
\hline Median Range & $0.3-7.2$ & $1.2-14.5$ & $1.8-7.6$ & & $1.6-13.1$ & $1.6-13.1$ & $0.3-14.5$ & \\
\hline \multicolumn{9}{|l|}{ Functional status } \\
\hline Non-functional & $\begin{array}{l}62 \\
(41.3 \%)\end{array}$ & $88(55.7 \%)$ & $44(68.7 \%)$ & & $72(66.7 \%)$ & $116(67.4 \%)$ & $266(55.4 \%)$ & \\
\hline Functional $^{\mathbf{B}}$ & $88(58.7 \%)$ & 70 (44.3\%) & $20(31.3 \%)$ & & $36(33.3 \%)$ & $56(32.6 \%)$ & $214(44.6 \%)$ & \\
\hline Incidental diagnosis & $\begin{array}{l}35 \\
(23.3 \%)\end{array}$ & 46 (29.1\%) & $14(21.9 \%)$ & & $25(23.1 \%)$ & 39 (22.7\%) & $120(25.0 \%)$ & \\
\hline Diagnosis after 2010 & $\begin{array}{l}98 \\
(65.3 \%)\end{array}$ & $108(68.4 \%)$ & $54(84.4 \%)$ & & 89 (82.4\%) & $143(83.1 \%)$ & $349(72.7 \%)$ & \\
\hline \multicolumn{9}{|l|}{ Tumor location } \\
\hline Body/tail & $\begin{array}{l}85 \\
(56.7 \%)\end{array}$ & $100(63.3 \%)$ & $43(67.2 \%)$ & & $68(62.9 \%)$ & $111(64.5 \%)$ & $296(61.7 \%)$ & \\
\hline \multicolumn{9}{|l|}{ Surgical margin } \\
\hline "ROC & $\begin{array}{l}126 \\
(84.0 \%)\end{array}$ & $124(78.5 \%)$ & $33(82.5 \%)$ & & $46(70.7 \%)$ & $89(84.8 \%)$ & 339 (70.6\%) & \\
\hline Postoperative medical therapy ${ }^{\mathbf{D}}$ & $\begin{array}{l}31 \\
(20.7 \%)\end{array}$ & $41(25.9 \%)$ & $29(45.3 \%)$ & & $61(56.5 \%)$ & $90(52.3 \%)$ & $162(33.8 \%)$ & \\
\hline Vascular infiltration & $\begin{array}{l}16 \\
(10.7 \%)\end{array}$ & $32(20.3 \%)$ & $16(25.0 \%)$ & & $35(32.4 \%)$ & $51(29.7 \%)$ & $99(45.3 \%)$ & \\
\hline Lymph involvement & $\begin{array}{l}35 \\
(23.3 \%)\end{array}$ & $52(32.9 \%)$ & $22(34.4 \%)$ & & $50(46.3 \%)$ & $72(41.9 \%)$ & 159 (33.1\%) & \\
\hline Distant metastasis $^{\mathbf{E}}$ & $\begin{array}{l}20 \\
(13.3 \%)\end{array}$ & $30(19.0 \%)$ & $12(18.7 \%)$ & & $32(29.6 \%)$ & $44(25.6 \%)$ & $94(19.6 \%)$ & \\
\hline Hepatic & $12(8.0 \%)$ & 15 (9.5\%) & $6(9.4 \%)$ & & $20(18.5 \%)$ & $26(15.1 \%)$ & $51(10.6 \%)$ & \\
\hline Bone & $5(3.3 \%)$ & $8(5.1 \%)$ & \multicolumn{2}{|c|}{$3(4.7 \%)$} & $10(9.3 \%)$ & $13(7.5 \%)$ & \multicolumn{2}{|c|}{$26(5.4 \%)$} \\
\hline Lymph nodal & $10(6.6 \%)$ & $14(8.9 \%)$ & \multicolumn{2}{|c|}{$4(6.3 \%)$} & $16(14.8 \%)$ & $20(11.6 \%)$ & \multicolumn{2}{|c|}{$44(9.2 \%)$} \\
\hline Out of contact & $\begin{array}{l}30 \\
(20.0 \%)\end{array}$ & $38(24.1 \%)$ & \multicolumn{2}{|l|}{$9(14.1 \%)$} & $23(21.3 \%)$ & $32(18.6 \%)$ & \multicolumn{2}{|l|}{$100(20.4 \%)$} \\
\hline Dead at follow-up & $\begin{array}{l}44 \\
(36.7 \%)\end{array}$ & $48(40.0 \%)$ & \multicolumn{2}{|l|}{$28(50.9 \%)$} & $56(69.1 \%)$ & $84(60.0 \%)$ & \multicolumn{2}{|l|}{$176(46.3 \%)$} \\
\hline 5-year OS & $75.8 \%$ & $58.4 \%$ & \multicolumn{2}{|l|}{$35.1 \%$} & $11.1 \%$ & $21.2 \%$ & \multicolumn{2}{|l|}{$53.0 \%$} \\
\hline MST, mons. & 85.3 & 67.4 & \multicolumn{2}{|l|}{51.3} & 26.8 & 34.5 & \multicolumn{2}{|l|}{63.1} \\
\hline \multirow{3}{*}{$\begin{array}{l}\text { TNM staging system by AJCC } 2017 \text { 8th } \\
\text { staging manual F } \\
\text { Stage I } \\
\text { Stage II } \\
\text { Stage III } \\
\text { Stage IV }\end{array}$} & \multicolumn{4}{|c|}{ WHO 2017 NET G1/G2/G3 $(N=372)$} & \multicolumn{4}{|c|}{ WHO $2017 \mathrm{NEC} \mathrm{G3}^{\mathrm{G}}(N=108)$} \\
\hline & Cases(\%) & $\begin{array}{l}\text { Out of } \\
\text { contact }\end{array}$ & $\begin{array}{l}\text { Dead at } \\
\text { follow-up }\end{array}$ & $\begin{array}{l}5 \text {-year } \\
\text { OS }\end{array}$ & Cases(\%) & Out of contact & $\begin{array}{l}\text { Dead at } \\
\text { follow-up }\end{array}$ & $\begin{array}{l}\text { 3-year } \\
\text { OS }\end{array}$ \\
\hline & $\begin{array}{l}116 \\
(31.2 \%)\end{array}$ & $\begin{array}{l}16(13.8 \%) \\
20(18.5 \%)\end{array}$ & $\begin{array}{l}19(19.0 \%) \\
23(26.1 \%)\end{array}$ & $\begin{array}{l}89.2 \% \\
70.5 \%\end{array}$ & $\begin{array}{l}18(16.7 \%) \\
30(27.8 \%)\end{array}$ & $\begin{array}{l}6(33.7 \%) \\
10(33.3 \%)\end{array}$ & $\begin{array}{l}6(50.0 \%) \\
13(65.0 \%)\end{array}$ & $\begin{array}{l}80.8 \% \\
33.2 \%\end{array}$ \\
\hline
\end{tabular}


Table 2 Clinical features of p-NENs in the present study according to the WHO 2017 and 2010 grading classification (Continued)

\begin{tabular}{|c|c|c|c|c|c|c|c|c|}
\hline \multirow[t]{2}{*}{ Factor } & \multicolumn{2}{|c|}{$\begin{array}{l}\text { WHO 2017/2010 } \\
\text { criteriaA }^{A}\end{array}$} & \multicolumn{3}{|c|}{ WHO 2017 criteria $^{A}$} & \multirow{2}{*}{$\begin{array}{l}\text { WHO } 2010 \\
\text { criteria }^{\mathbf{A}} \\
\text { "NEC G3" } \\
(\boldsymbol{N}=172)\end{array}$} & \multirow[b]{2}{*}{$\begin{array}{l}\text { All } \\
(\boldsymbol{N}=480)\end{array}$} & \\
\hline & $\begin{array}{l}\text { NET G1 } \\
(\boldsymbol{N}=150)\end{array}$ & $\begin{array}{l}\text { NET G2 } \\
(\boldsymbol{N}=158)\end{array}$ & $\begin{array}{l}\text { NET G3 } \\
(\boldsymbol{N}=64)\end{array}$ & & $\begin{array}{l}\text { NEC G3 } \\
(\boldsymbol{N}=108)\end{array}$ & & & \\
\hline & $\begin{array}{l}108 \\
(29.1 \%) \\
86 \\
(23.1 \%) \\
62 \\
(16.6 \%)\end{array}$ & $\begin{array}{l}20(23.6 \%) \\
20(32.3 \%)\end{array}$ & $\begin{array}{l}41(62.1 \%) \\
37(88.1 \%)\end{array}$ & $\begin{array}{l}51.2 \% \\
18.9 \%\end{array}$ & $\begin{array}{l}28(25.9 \%) \\
32(29.6 \%)\end{array}$ & $\begin{array}{l}2(7.1 \%) \\
6(18.8 \%)\end{array}$ & $\begin{array}{l}19(73.1 \%) \\
18(69.2 \%)\end{array}$ & $\begin{array}{l}7.1 \% \\
\text { NA }\end{array}$ \\
\hline
\end{tabular}

A: The NET G1 and NET G2 were consistently defined in WHO 2017 and 2010 grading criteria for p-NENs, while the "NEC G3" of WHO 2010 criteria was composed of both NET G3 and NEC G3 of WHO 2017 criteria $[8,14]$

B: Referring to insulinoma, gastrinoma, vasoactive intestinal polypeptidoma, adrenocorticotropic hormone adenoma, glucagonoma, pheochromocytoma, etc.

C: Referring to radical resections with both grossly and microscopically negative surgical margins

D: Referring to conventional chemotherapy and novel molecular targeted therapies

E: Distant metastases (hepatic, bone, lymph nodal) for patients with p-NENs was present at diagnosis

F: In the AJCC 2017 staging manual, one TNM system was originally proposed for G1/G2 p-NETs, the other for "G3 p-NECs" of WHO 2010 criteria

G: The G3 p-NETs of WHO 2017 grading classification were also staged by the system for G1/G2 p-NETs, while the G3 p-NECs of WHO 2017 criteria were staged

by the system for pancreatic exocrine adenocarcinomas, as we have demonstrated in the previous report [19]

Abbreviations: $p$-NENs Pancreatic neuroendocrine neoplasms; WHO World Health Organization; NET Neuroendocrine tumors; NEC Neuroendocrine carcinoma; $G$

Grading; TNM Tumor-node-metastasis; AJCC American Joint Committee On Cancer; NA Not applicable; OS Overall survival; MST Median survival time

grading classification for p-NENs represented an important step toward adopting a uniform grading system with widespread acceptance, its weakness appeared gradually.

Firstly, WHO suggested the higher of the two parameters be used to assign the final grade (typically, the Ki-67 index often pointed to the higher WHO grade) when mitotic rate and $\mathrm{Ki}-67$ index were sometimes discordant [8]. This would inevitably increase the number of cases of "G3 p-NECs", which was demonstrated by Basturk et al. that mitotic G2/Ki-67 "G3 p-NECs" biologically behaved more like mitotic G2/Ki-67 G2 p-NETs [22]. They found that p-NENs with a Ki-67 proliferative index >
$20 \%$, if well-differentiated, were more aggressive than G2 but significantly less aggressive than "G3 p-NECs" with poorly differentiated features (large or small cell type) [22]. Furthermore, the WHO 2010 grading classification just used the terminology "high-grade" and "poorly-differentiated" interchangeably for neoplasms in the G3 category, while recent studies have further focused on the heterogeneity of "G3 p-NECs", in which some might primarily present a high $\mathrm{Ki}-67$ proliferative rate but be morphologically well-differentiated [23]. Sorbye et al. demonstrated the WHO 2010 "G3 p-NECs" were morphologically and biologically heterogenous, in which they

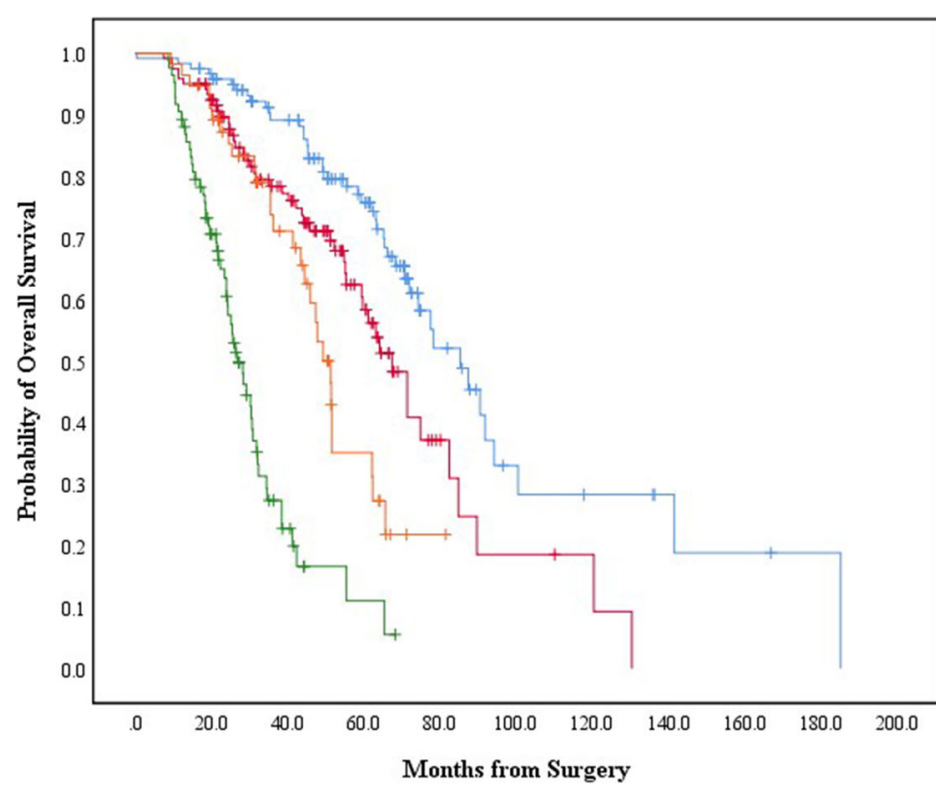

WHO 2017 grading
criteria for p-NENs
$\neg$ G1 p-NETs
$\neg$ G2 p-NETs
$\neg$ G3 p-NECs
G3 p-NETs
G1 p-NETs- Censoring
+ G2 p-NETs- Censoring
- G3 p-NECs- Censoring
G3 p-NETs- Censoring

Fig. 1 Kaplan-Meier estimates for the OS of p-NENs, according to the WHO 2017 grading classification 


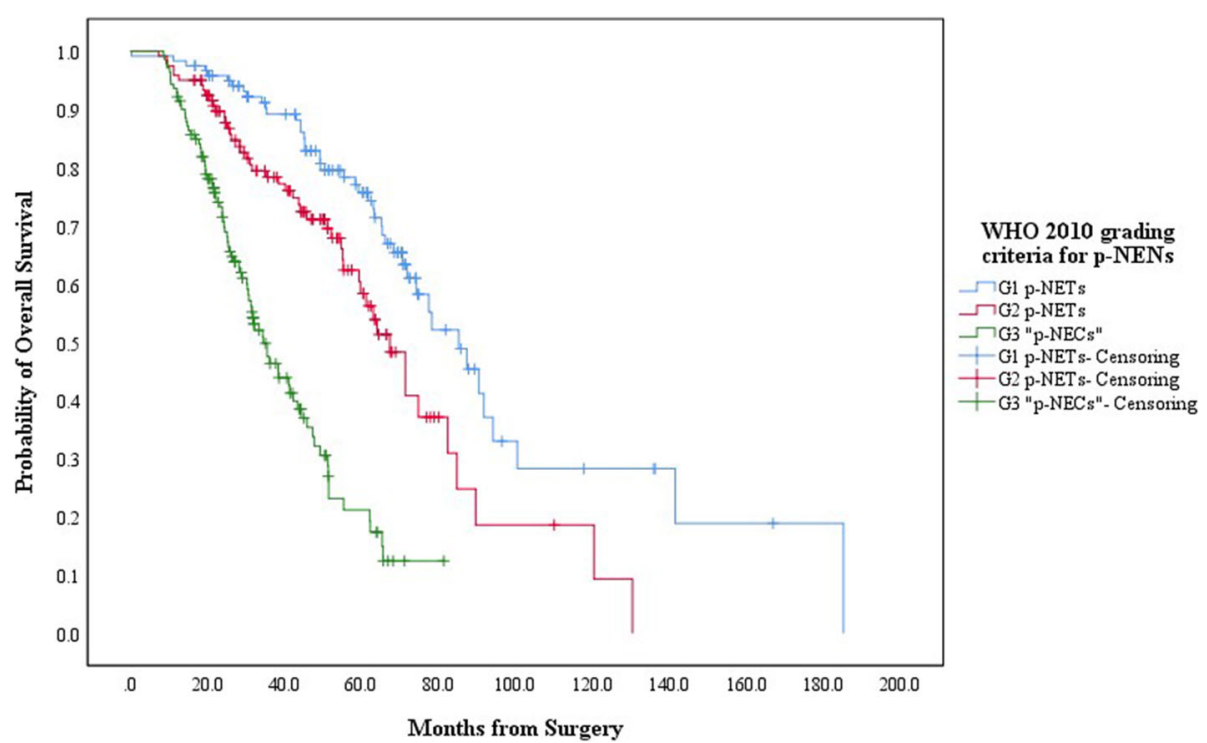

Fig. 2 Kaplan-Meier estimates for the OS of p-NENs, according to the WHO 2010 grading classification

reported a lower response rate after platinum-based systemic chemotherapy $(15 \%$ vs. $42 \%$, respectively; $P<$ $0.05)$, but a longer MST (14mon vs. 10mon, respectively; $P<0.05)$ among tumors with a Ki-67<55\%, compared with those having a higher Ki-67 index [7]. Similar conclusions have also been reached that G3 p-NENs might consist of two distinct subgroups: welldifferentiated $\mathrm{p}$-NETs with a high proliferative rate (grade-discordant G2 p-NETs or morphologically G3 p-NETs) and true poorly-differentiated p-NECs (small-cell or large-cell G3 p-NECs) [24-26].
The previous work eventually formed the basis for the WHO grading classification published in 2017 (Table 1), which officially defined p-NENs into two broad categories (well-differentiated and poorly-differentiated) and four groups (NET G1/G2/G3 and NEC G3) in the light of both morphological differentiation and grading upon proliferation rate [14]. However, this new system has not yet been validated. According to the comprehensive analysis of p-NENs in the present study, we revealed three major findings. First, the WHO 2017 grading classification could well distribute p-NENs into four significant groups with different clinical features and long-term

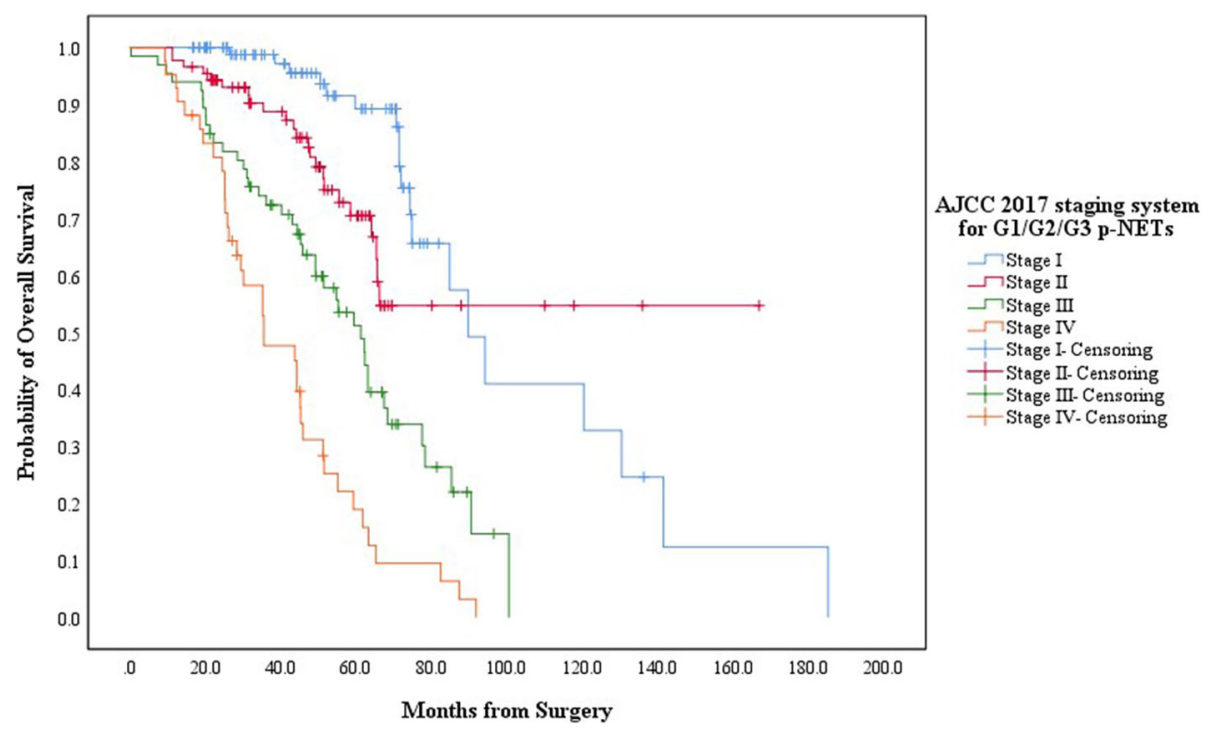

Fig. 3 Kaplan-Meier estimates for the OS of G1/G2/G3 p-NETs, according to the AJCC 2017 staging system originally proposed for G1/G2 p-NETs 


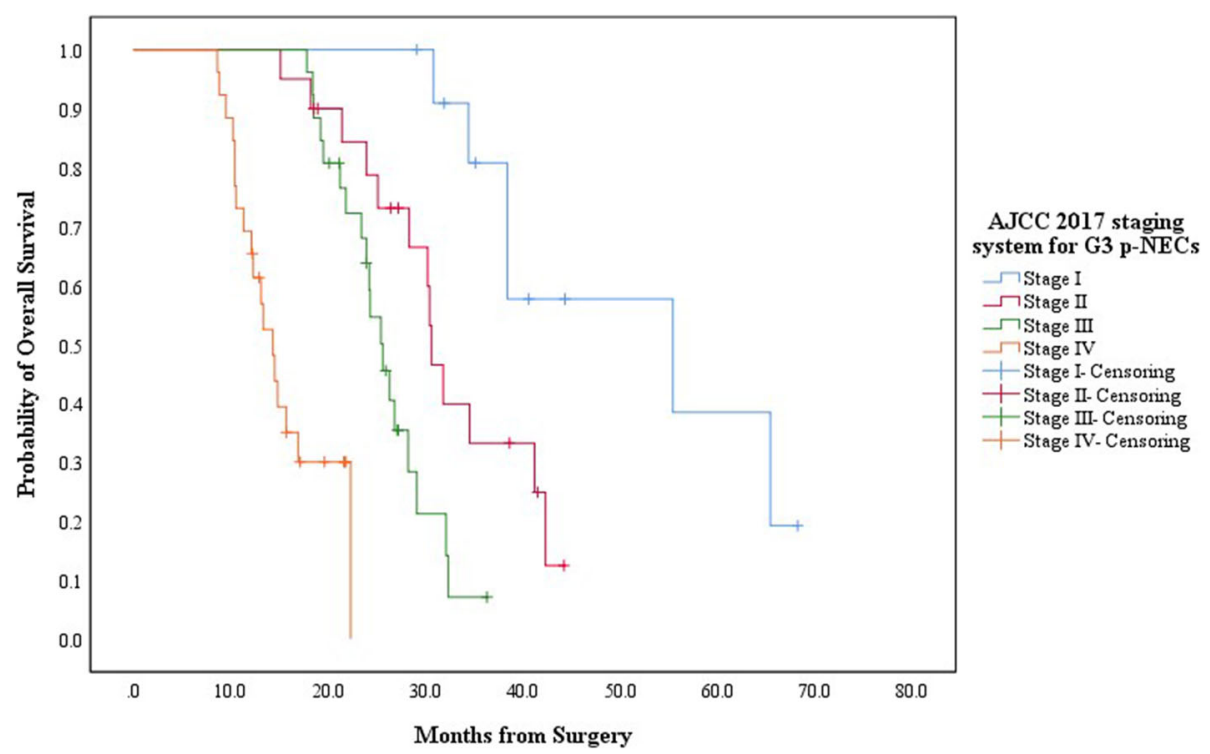

Fig. 4 Kaplan-Meier estimates for the OS of G3 p-NECs, according to the AJCC 2017 staging system originally proposed for "G3 p-NECs"

survivals. Second, the new WHO system was superior to WHO 2010 criteria for better stratifying ability and more accurate predicting ability for the OS of p-NENs. Finally, patients with different WHO 2017 grading p-NENs could be well staged by the new AJCC 8th TNM staging manual.

According to the definitions of WHO 2017 and 2010 grading classification for $\mathrm{p}$-NENs, their main difference was that the WHO 2010 "G3 p-NECs" group was now divided into WHO 2017 G3 p-NET and G3 p-NECs (Table 1). We have just reported in one study that comparisons of patient demographics and tumor characteristics of G3 p-NETs and G3 p-NECs weren't significant $(P>0.05)$, although the tumor diameter of G3 p-NETs seemed be smaller than that of G3 p-NECs $(4.5 \mathrm{~cm}$ vs. $5.6 \mathrm{~cm}$, respectively; $P=0.059$ ) [27]. Hereby, in Table 2, comprehensive comparisons were made for related factors between well-differentiated neoplasms (i.e. G1/G2/G3 pNETs) and poorly-differentiated ones (i.e. G3 p-NECs). We found that the patient age of G1/G2/G3 p-NETs was notably younger than that of G3 p-NECs ( $3.5 \mathrm{~cm}$ vs. 5.6 $\mathrm{cm}$, respectively; $P=0.027$ ) and the tumor diameter of G1/G2/G3 p-NETs was statistically smaller than that of G3 p-NECs (50 yrs. vs. 57 yrs., respectively; $P=0.034$ ). Meanwhile, compared with G1/G2/G3 p-NETs, G3 pNECs present significantly more vascular infiltration (32.4\% vs. $17.2 \%$, respectively; $P=0.035$ ), lymph involvement ( $46.3 \%$ vs. $29.3 \%$, respectively; $P=0.019$ ) and distant metastasis $(29.6 \%$ vs. $16.7 \%$, respectively; $P=0.041)$. Referring to the results above [27], statistical differences of these clinicopathological features might be caused by the integration of G1/G2/G3 neoplasms, forming the category of well-differentiated p-NENs, as McCall et al. have demonstrated in their study [28].
G1/G2/G3 p-NETs were usually slow-growing tumors with equal sex preference occurring over a broad age range, highest incidence peak between third and sixth decade, while G3 p-NECs had an incidence peak in the sixth to seventh decade, whose clinical presentation was very similar to pancreatic exocrine adenocarcinomas ( $p$ EACs) [17]. Our analysis indicated that patient gender among each new grading group had a slight female predominance with a peak median incidence age ranging from 45 yrs. to $57 \mathrm{yrs}$. and that p-NENs more frequently involved the body or tail of pancreas (Table 2). In terms of the survival of p-NENs, the WHO 2017 and 2010 grading classification both showed significantly decreased survivals as grade increased (Fig. 1, Fig. 2; respectively). Most importantly, the estimated 5-year OS of G3 p-NETs was statistically better than that of G3 p-NECs ( $35.1 \%$ vs. $11.1 \%$, respectively; $P<0.001$ ) but notably worse than that of $\mathrm{G} 2$ p-NETs (35.1\% vs. $58.4 \%$, respectively; $P=0.023)$ and $G 1$ p-NETs $(35.1 \%$ vs. $75.8 \%$, respectively; $P<0.001$; Fig. 1$)$. This situation was in agreement with the reported results we mentioned above [25-27]. We then revealed that although the WHO 2017 and 2010 criteria could be independent predictor for the OS of p-NENs $(P=0.016, P=$ 0.022, respectively; Table 3), the 95\% CIs of WHO 2017 grading classification (0.983-9.454) was slightly smaller than that of WHO 2010 criteria (0.201-13.374), indicating a relatively better predicting accuracy.

Another concern of our analysis was the TNM staging classification for p-NENs. In 2010, AJCC began to apply its TNM staging system to p-NENs [19], which derived from the staging algorithm for p-EACs and was proven to be convenient but a little oversimplified for p-NENs $[29,30]$. In 2017, AJCC updated its staging manual for 
Table 3 Univariate and multivariate analysis of factors with the OS of p-NENs using Cox Regression proportional hazard models

\begin{tabular}{|c|c|c|c|}
\hline \multirow[t]{2}{*}{ Factor } & Univariate Analysis & WHO 2017 criteria Multivariate Analysis $^{\mathbf{A}}$ & WHO 2010 criteria Multivariate Analysis ${ }^{\mathbf{A}}$ \\
\hline & $\mathrm{HR}(95 \% \mathrm{Cls}) \mathrm{P}$ & $\mathrm{HR}(95 \% \mathrm{Cls}) \mathrm{P}$ & $\mathrm{HR}(95 \% \mathrm{Cls}) \mathrm{P}$ \\
\hline \multicolumn{4}{|l|}{ Gender } \\
\hline \multicolumn{4}{|l|}{ Male ${ }^{\mathbf{B}}$} \\
\hline Female & $0.953(0.467-3.252) 0.537$ & & \\
\hline \multicolumn{4}{|l|}{ Age, yr. } \\
\hline \multicolumn{4}{|l|}{$<$ Median } \\
\hline$\geq$ Median & $1.211(0.587-1.256) 0.079$ & & \\
\hline \multicolumn{4}{|l|}{ Tumor location } \\
\hline \multicolumn{4}{|l|}{ Head } \\
\hline Body/tail & $1.436(0.912-2.579) 0.408$ & & \\
\hline \multicolumn{4}{|l|}{ Functional status } \\
\hline \multicolumn{4}{|l|}{ Functional } \\
\hline Non-functional & $1.725(0.436-3.926) \mathbf{0 . 0 2 7}$ & $0.894(0.583-1.457) 0.635$ & $0.616(0.589-1.368) 0.441$ \\
\hline \multicolumn{4}{|c|}{ Incidental diagnosis } \\
\hline \multicolumn{4}{|l|}{ No } \\
\hline Yes & $0.984(0.457-1.562) 0.336$ & & \\
\hline \multicolumn{4}{|l|}{ Radical resection } \\
\hline \multicolumn{4}{|l|}{ Yes } \\
\hline No & $4.113(0.384-7.335)<0.001$ & $0.993(0.309-1.873) 0.009$ & $1.023(0.574-2.359) \mathbf{0 . 0 1 5}$ \\
\hline \multicolumn{4}{|c|}{ Postoperative medical therapy } \\
\hline \multicolumn{4}{|l|}{ Yes } \\
\hline No & $1.518(0.366-2.735) \mathbf{0 . 0 4 5}$ & $0.845(0.673-1.419) 0.357$ & $0.903(0.449-1.525) 0.745$ \\
\hline \multicolumn{4}{|l|}{ Tumor diameter } \\
\hline \multicolumn{4}{|l|}{$<$ Median } \\
\hline$\geq$ Median & $1.005(0.567-2.138) \mathbf{0 . 0 2 4}$ & $0.665(0.357-1.983) 0.341$ & $0.883(0.436-1.843) 0.452$ \\
\hline \multicolumn{4}{|l|}{ Vascular infiltration } \\
\hline \multicolumn{4}{|l|}{ No } \\
\hline Yes & $2.138(0.543-4.113) \mathbf{0 . 0 3 7}$ & $1.255(0.843-2.059) \mathbf{0 . 0 1 2}$ & $0.993(0.519-1.725) \mathbf{0 . 0 3 9}$ \\
\hline \multicolumn{4}{|c|}{ Lymph involvement } \\
\hline \multicolumn{4}{|l|}{ No } \\
\hline Yes & $3.542(0.343-6.25) \mathbf{0 . 0 0 8}$ & $2.357(0.331-5.369) \mathbf{0 . 0 3 6}$ & $1.924(0.536-3.454) \mathbf{0 . 0 2 5}$ \\
\hline \multicolumn{4}{|l|}{ Distant metastasis } \\
\hline \multicolumn{4}{|l|}{ No } \\
\hline Yes & $5.112(0.478-10.205)<\mathbf{0 . 0 0 1}$ & $4.124(0.385-8.359) \mathbf{0 . 0 2 7}$ & $2.445(0.501-7.374) \mathbf{0 . 0 4 8}$ \\
\hline \multicolumn{4}{|c|}{ Grading by WHO 2010 criteria } \\
\hline \multicolumn{4}{|l|}{ NET G1/G2 } \\
\hline "NEC G3" & $4.425(0.454-14.346)<\mathbf{0 . 0 0 1}$ & NA & $2.445(0.201-13.374) \mathbf{0 . 0 2 2}$ \\
\hline \multicolumn{4}{|c|}{ Grading by WHO 2017 criteria } \\
\hline \multicolumn{4}{|l|}{ NET G1/G2/G3 } \\
\hline NEC G3 & $6.634(0.634-8.257)<0.001$ & $4.562(0.983-9.454) \mathbf{0 . 0 1 6}$ & NA \\
\hline
\end{tabular}

A: Predicting value of the WHO 2017 and 2010 grading classification for the OS of p-NENs was built and evaluated in separate Regression proportional hazard models

B: The above one of related factor was regarded as a reference in Cox analysis

Abbreviation: OS Overall survival; $p$-NENs Pancreatic neuroendocrine neoplasms; WHO World Health Organization; HR Hazard ratio; Cls Confidence intervals; NET Neuroendocrine tumors; NEC Neuroendocrine carcinoma; G Grading; NA Not applicable 
p-NENs (i.e. 8th edition), in which AJCC highlighted that the novel system for p-NENs should only be applied to G1/G2 p-NETs, while "G3 p-NECs" be staged by the revised one for p-EACs [18]. The two new independent AJCC staging systems for p-NENs have been separately demonstrated to be superior to the AJCC 7th edition system in two previous studies [31,32]. Recently, considering the heterogeneity with "G3 p-NECs", we for the first time attempted to evaluate which new system G3 pNETs should be better staged by [27]. We concluded that the AJCC 8th staging systems introduced for G1/G2 pNETs and "G3 p-NECs" were both practical for G3 pNETs, while the one originally applied to G1/G2 p-NETs appeared to be superior in performance [27]. Therefore, in the present study, we firstly staged G1/G2/G3 p-NETs together by one new AJCC system for G1/G2 p-NETs and staged G3 p-NECs by the other one for "G3 p-NECs" (Table 2). According to our analysis, both G1/G2/G3 pNETs and G3 p-NECs could be well classified into four prognostic groups by their corresponding AJCC system, respectively, with statistically different stage distributions on their OS ( $P<0.05$; Fig. 3 and Fig. 4$)$.

Our study had some limitations. First of all, it was also a retrospective study in which data analysis and patient's recruitment were over a long duration. Secondly, the accumulative OS was estimated by K-M methods due to some cases with a short follow-up time. Then, our analysis derived from one single medical institution which might reduce the statistical power between factors and survival outcomes. Finally, all patients had surgicallyresected disease and applicability to patients presenting with advanced disease needs to be validated. Hereby, a particular implication for patients with G3 p-NECs, particularly those with metastatic disease at presentation, given that surgery would not be considered as standard management for most patients with G3 p-NECs [33-35]. Therefore, a prospectively designed study from multi centers and with a long follow-up time is still needed to confirm our results.

\section{Conclusion}

In a word, we concluded that the WHO 2017 grading classification for p-NENs could successfully allocate patients into four groups with distinct clinical features and significant survival differences, which might be superior to the WHO 2010 criteria for its better prognostic stratification and more accurate predicting ability. Our demonstration supported the wide use of WHO 2017 grading classification to p-NENs in current clinical practice.

\section{Abbreviations}

P-NENs: Pancreatic neuroendocrine neoplasms; ENETS: European neuroendocrine tumor society; HPFs: High power fields; G: Grading; pNETs: Pancreatic neuroendocrine tumors; G3 p-NECs: Pancreatic neuroendocrine carcinomas; WHO: World health organization; TNM: Tumor- node-metastasis; AJCC: American joint committee on cancer; MST: Median survival time; HR: Hazard ratio; Cls: Confidence intervals; SD: Standard deviation; K-M: Kaplan-meier; p-EACs: Pancreatic exocrine adenocarcinomas.

\section{Acknowledgements}

Not applicable.

\section{Authors' contributions}

In this paper, YM. contributed to this work as first author; ZY. and XB. contributed equally as senior author. $Z Y$. and $X B$. designed the research and approved the final manuscript; YM. extracted the data and wrote the manuscript; ZY. and XB. corrected the manuscript; ZL. and TC.L. made the tables and figures; KN.W. carried out the reference review and statistical analysis; TB.L. and LX.B. had important intelligent contributions to the manuscript. All authors red and approved the final manuscript.

\section{Funding}

We declared that we didn't have any sponsorship.

\section{Availability of data and materials}

The data and materials of our present research couldn't be shared at this time as the data and materials also formed part of an ongoing study, while they could be available in the near future from the corresponding author upon request after the accomplishment of our ongoing study.

\section{Ethics approval and consent to participate}

Our research was approved by the institutional review board of West China Hospital of Sichuan University and written informed consent was acquired on admission from all patients for their information to be used for studying purpose, which was in accordance with the general principles of the Helsinki Declaration.

\section{Consent for publication}

The written informed consent was acquired on admission from all patients for their information to be used for studying purpose.

\section{Competing interests}

We declared that we had no conflict of interest among the authors.

\section{Author details}

${ }^{1}$ Department of Pediatric Surgery, West China Hospital of Sichuan University, Chengdu, Sichuan Province, the People's Republic of China. ${ }^{2}$ President \& Dean's Office, West China Hospital of Sichuan University, Chengdu, Sichuan Province, the People's Republic of China. ${ }^{3}$ Department of Pancreatic Surgery, West China Hospital of Sichuan University, Chengdu, Sichuan Province, the People's Republic of China, No.37, Guoxue Road, Wuhou District, Chengdu, Sichuan Province, the People's Republic of China.

Received: 7 April 2020 Accepted: 27 August 2020

Published online: 22 September 2020

References

1. Kloppel G, Perren A, Heitz PU. The gastroenteropancreatic neuroendocrine cell system and its tumors: the WHO classification. Ann N Y Acad Sci. 2004; 1014:13-27.

2. Yao JC, Hassan M, Phan A, Dagohoy C, Leary C, Mares JE, et al. One hundred years after "carcinoid": epidemiology of and prognostic factors for neuroendocrine tumors in 35,825 cases in the United States. J Clin Oncol. 2008;26:3063-72.

3. Korse $C M$, Taal BG, van Velthuysen ML, Visser O. Incidence and survival of neuroendocrine tumours in the Netherlands according to histological grade: experience of two decades of cancer registry. Eur J Cancer. 2013;49: 1975-83.

4. Dasari A, Shen C, Halperin D, Zhao B, Zhou S, Xu Y, et al. Trends in the incidence, prevalence, and survival outcomes in patients with neuroendocrine tumors in the United States. JAMA Oncol. 2017:3:1335-42.

5. Niederle MB, Hackl M, Kaserer K, Niederle B. Gastroenteropancreatic neuroendocrine tumours: the current incidence and staging based on the WHO and European neuroendocrine tumour society classification: an analysis based on prospectively collected parameters. Endocr Relat Cancer. 2010;17:909-18. 
6. Rindi G, Klöppel G, Alhman H, Caplin M, Couvelard A, de Herder WW, et al. TNM staging of foregut (neuro) endocrine tumors: a consensus proposal including a grading system. Virchows Arch. 2006;449:395-401.

7. Sorbye H, Welin S, Langer SW, Vestermark LW, Holt N, Osterlund P, et al. Predictive and prognostic factors for treatment and survival in 305 patients with advanced gastrointestinal neuroendocrine carcinoma (WHO G3): the NORDIC NEC study. Ann Oncol. 2013;24:152-60.

8. Rindi G, Arnold R, Bosman FT, Capella C, Klimstra DS, Kloppel G, et al. Nomenclature and classification of neuroendocrine neoplasms of the digestive system. In: Bosman FT, Carneiro F, Hruban RH, Theise ND, editors. WHO classification of tumours of the digestive system. 4th ed. Lyon: International Agency for Research on cancer; 2010. p. 13-40.

9. Panzuto F, Boninsegna L, Fazio N, Campana D, Brizzi MP, Capurso G, et al. Metastatic and locally advanced pancreatic endocrine carcinomas: analysis of factors associated with disease progression. J Clin Oncol. 2011;29:2372-7.

10. Dolcetta-Capuzzo A, Villa V, Albarello L, Franchi GM, Gemma M, Scavini M, et al. Gastroenteric neuroendocrine neoplasms classification: comparison of prognostic models. Cancer. 2013;119:36-44.

11. Kunz PL, Reidy-Lagunes D, Anthony LB, Bertino EM, Brendtro K, Chan JA et al. Consensus guidelines for the management and treatment of neuroendocrine tumors. Pancreas. 2013;42:557-77.

12. Yang M, Tian BL, Zhang Y, Su AP, Yue PJ, Xu S, et al. Evaluation of the World Health Organization 2010 grading system in surgical outcome and prognosis of pancreatic neuroendocrine tumors. Pancreas. 2014;43:1003-8.

13. Yang $M$, Ke NW, Zeng $L$, Zhang $Y$, Tan $C L$, Zhang $H$, et al. Survival analyses for patients with surgically resected pancreatic neuroendocrine tumors by world health organization 2010 grading classifications and american joint committee on cancer 2010 staging systems. Medicine (Baltimore). 2015;94:e2156.

14. Klöppel G, Couvelard A, Hruban RH, Klimstra DS, Komminoth P, Osamura RY, et al. Tumours of the endocrine pancreas. In: Lloyd RV, Osamura RY, Klöppel G, Rosai J, editors. WHO classification of the Tumours of endocrine organs. 4th ed. Lyon, France: International Agency for Research on Cancer; 2017. p. 175-207.

15. Crawley FP. The limits of the declaration of Helsinki. In: address to scientific session. Helsinki: World Medical Association General Assembly; 2012.

16. Solcia E, Carlo C. Endocrine tumours of the gastrointestinal tract. Histologic typing of endocrine tumours. WHO international histological classification of tumours. Heidelberg-New York: Springer Verlag; 2000. p. 57-67.

17. Guilmette JM, Nosé V. Neoplasms of the neuroendocrine pancreas: an update in the classification, definition, and molecular genetic advances. Adv Anat Pathol. 2019;26:13-30

18. Kakar S, Pawlik TM, Allen PJ, editors. AJCC Cancer staging manual. 8th ed. New York, NY: Springer-Verlag; 2017.

19. Edge SB, Byrd DR, Compton CC, et al. AJCC Cancer staging manual. New York, NY: Springer; 2010.

20. Capella C, Heitz PU, Hofler H, Solcia E, Kloppel G. Revised classification of neuroendocrine tumours of the lung, pancreas and gut. Virchows Arch. 1995:425:547-60.

21. Heitz $P$, Komminoth $P$, Perren A, eds. Tumours of the Endocrine Pancreas. International Agency for Research on Cancer (IARC), Lyon, France, 2004: 177-182..

22. Basturk O, Yang Z, Tang LH, Hruban RH, Adsay V, McCall CM, et al. The highgrade (WHO G3) pancreatic neuroendocrine tumor category is morphologically and biologically heterogenous and includes both well differentiated and poorly differentiated neoplasms. Am J Surg Pathol. 2015; 39:683-90.

23. Cavalcanti MS, Gönen M, Klimstra DS. The ENETS/WHO grading system for neuroendocrine neoplasms of the gastroenteropancreatic system: a review of the current state, limitations and proposals for modifications. Int J Endocr Oncol. 2016;3:203-19.

24. Tang LH, Untch BR, Reidy DL, O'Reilly E, Dhall D, Jih L, et al. Welldifferentiated neuroendocrine tumors with a morphologically apparent high grade component: a pathway distinct from poorly differentiated neuroendocrine carcinomas. Clin Cancer Res. 2016;22:1011-7.

25. Tang LH, Basturk O, Sue JJ, Klimstra DS. A practical approach to the classification of WHO grade 3 (G3) well differentiated neuroendocrine tumor (WD-NET) and poorly differentiated neuroendocrine carcinoma (PDNEC) of the pancreas. Am J Surg Pathol. 2016:40:1192-202.

26. Kim JY, Hong SM, Ro JY. Recent updates on grading and classification of neuroendocrine tumors. Ann Diagn Pathol. 2017;29:11-6.

27. Deng BY, Yang M, Wen JY, Hou SZ, Chen Y, Tian BL, et al. Survivals of patients with pancreatic neuroendocrine carcinomas: An in-depth analysis by the American Joint Committee on Cancer 8th tumor-node-metastasis staging manual. Medicine (Baltimore). 2020;99:e18736.

28. McCall CM, Shi C, Cornish TC, Klimstra DS, Tang LH, Basturk O, et al. Grading of well-differentiated pancreatic neuroendocrine tumors is improved by the inclusion of both Ki67 proliferative index and mitotic rate. Am J Surg Pathol. 2013:37:1671-7

29. Rindi G, Falconi M, Klersy C, Albarello L, Boninsegna L, Buchler MW, et al. TNM staging of neoplasms of the endocrine pancreas: results from a large international cohort study. J Natl Cancer Inst. 2012;104:764-77.

30. Cho JH, Ryu JK, Song SY, Hwang JH, Lee DK, Woo SM, et al. Prognostic validity of the American joint committee on Cancer and the European neuroendocrine tumors staging classifications for pancreatic neuroendocrine tumors: a retrospective Nationwide multicenter study in South Korea. Pancreas. 2016;45:941-6.

31. Yang M, Zhang $Y$, Zeng L, Ke NW, Tan CL, Tian BL, et al. Prognostic validity of the American joint committee on Cancer eighth edition TNM staging system for surgically treated and well-differentiated pancreatic neuroendocrine tumors: a comprehensive analysis of 254 consecutive patients from a large Chinese institution. Pancreas. 2019;48:613-21.

32. Yang M, Zhang Y, Zeng L, Ke NW, Tan CL, Tian BL, et al. Survivals of patients with surgically treated and high-grade pancreatic neuroendocrine carcinomas: a comparative study between two American joint committee on Cancer 8th tumor-node-metastasis staging systems. Eur J Surg Oncol. 2019:45:1054-60.

33. Pavel M, O'Toole D, Costa F, Capdevila J, Gross D, Kianmanesh R, et al. ENET $\mathrm{S}$ consensus quidelines update for the management of distant metastatic disease of intestinal, pancreatic, bronchial neuroendocrine neoplasms (NEN) and NEN of unknown primary site. Neuroendocrinology. 2016;103:172-85.

34. Garcia-Carbonero R, Sorbye H, Baudin E, Raymond E, Wiedenmann B, Niederle $B$, et al. ENETS consensus guidelines for high-grade gastroenteropancreatic neuroendocrine tumors and neuroendocrine carcinomas. Neuroendocrinology. 2016;103:186-94.

35. Falconi M, Eriksson B, Kaltsas G, Bartsch DK, Capdevila J, Caplin M, et al. ENETS consensus guidelines update for the management of patients with functional pancreatic neuroendocrine tumors and non-functional pancreatic neuroendocrine tumors. Neuroendocrinology. 2016;103:153-71.

\section{Publisher's Note}

Springer Nature remains neutral with regard to jurisdictional claims in published maps and institutional affiliations.
Ready to submit your research? Choose BMC and benefit from:

- fast, convenient online submission

- thorough peer review by experienced researchers in your field

- rapid publication on acceptance

- support for research data, including large and complex data types

- gold Open Access which fosters wider collaboration and increased citations

- maximum visibility for your research: over $100 \mathrm{M}$ website views per year

At BMC, research is always in progress.

Learn more biomedcentral.com/submissions 